\title{
History of falling and visual ability among independently living elderly in Sweden
}

\author{
This article was published in the following Dove Press journal: \\ Clinical Ophthalmology \\ II July 2016 \\ Number of times this article has been viewed
}

\section{Jeanette Källstrand- Eriksson' \\ Cathrine Hildingh' \\ Boel Bengtsson ${ }^{2}$}

'School of Health and Welfare, Halmstad University, Halmstad, ${ }^{2}$ Department of Clinical Sciences in Malmö, Ophthalmology, Lund University, Malmö, Sweden
Correspondence: Jeanette KällstrandEriksson

School of Health and Welfare, Halmstad University, Box 823, S-30I I8 Halmstad, Sweden

Tel +46 $35 \quad 167949$

Email jeanette.kallstrand_eriksson@hh.se
Purpose: The aim of this study was to assess the performance-based visual ability among independently living elderly subjects and to investigate whether there was any association between visual ability and falls.

Subjects and methods: A total of 298 randomly selected subjects aged 70-85 years were invited for an examination including monocular and binocular visual acuity (VA), contrast sensitivity (CS), stereoscopic vision, and monocular visual fields (VFs), which were integrated to estimate the binocular VFs. Type of lenses used in their habitual correction was noted.

Results: Out of the 212 subjects who were examined, 38\% reported at least one fall and 48\% of these reported at least two falls during the last 2 years. Most subjects had normal results; $90 \%$ had normal binocular VA, $85 \%$ had normal binocular CS, and $~ 80 \%$ had positive stereopsis. Twenty-nine subjects had VF defects in the lower quadrants of the binocular VF, and 14 of these reported at least one fall. A significant association was seen between one fall or more and VA better eye, the odds ratio (OR) was 2.26, $P=0.013$, and between recurrent falls and lack of stereoscopic vision, the OR was 3.23, $P=0.002$; no other functional test showed any significant association with recurrent falls. The ORs were 1.58 for worse binocular VA, 0.60 for worse binocular CS, and 0.71 for non-normal stereoscopic vision for at least one fall, but wide confidence intervals made it difficult to draw firm conclusions about any association. Bifocal or progressive spectacles were worn by $71 \%$ with no significant difference between fallers and nonfallers $(P=0.078)$.

Conclusion: Even though $\sim 40 \%$ of the total sample had experienced one or more falls, the only visual function test significantly associated with falls were VA better eye, lack of stereoscopic vision, and recurrent falls. Our results suggest that there may be more powerful predictors of falling than decreased visual ability.

Keywords: elderly, falls, independently living, visual ability

\section{Introduction}

Falls and fall injuries among older people are considered a major problem with negative consequences for both the individual and society. ${ }^{1,2}$ The number of falls is estimated to increase in many countries throughout the world since the aging population is increasing with at least one-third of elderly persons living in the community suffering a fall each year. ${ }^{3,4}$ The Swedish National Institute of Public Health estimates that deterioration in quality of life caused by accidental falls costs the society almost twice as much as do direct costs such as health care and rehabilitation. ${ }^{3}$ A major systematic review has identified as many as 400 potential risk factors for falling, and visual impairment was considered one of the most predictive for falling among independently living elderly people. ${ }^{1}$

Research has indicated that visual ability is of considerable importance for both quality of life and social functioning, and its loss or limitation can be a threat to 
independence and an active lifestyle. ${ }^{5}$ Deficits in vision and/or the ability to respond to visual cues may cause incorrect sensory inputs that would lead to difficulties in perceiving geographical environment, hazards, and moving stimuli. ${ }^{6,7}$

Several reports have indicated that elderly people with poor vision are at high risk of falling. ${ }^{8-10}$ Ocular diseases have also been reported to affect visual ability in different ways, and the use of multifocal glasses has been reported to affect contrast sensitivity (CS) and depth perception and may be a risk factor for falls. ${ }^{11-13}$ Studies about falls and visual ability have typically been accomplished in selected populations such as in those with specific ocular diseases. ${ }^{13-15}$ A review investigating falls and impaired vision claims that studies using different measures of vision are needed before making any conclusions about relationship between vision and falls. ${ }^{15}$ Therefore, a randomly selected sample from a population of independently living older people might be informative.

The aim of our study was to assess the performance-based visual ability among non-institutionalized independently living older subjects and to investigate whether there was any association between visual ability and falls.

\section{Subjects and methods}

This is a population-based study of independently living older people in the county of Halland, situated in the western part of Sweden. This study is a part of a larger project investigating perceived vision-related quality of life. ${ }^{16}$

\section{Subjects}

All subjects were randomly selected from the Swedish population-based listings of subjects between 70 years and 85 years of age living in three municipalities in Halland county. The selected subjects were invited by posted mail following a telephone call. The inclusion criteria were cognitive functioning and fluency in the Swedish language, to be ambulatory with or without using walking aids, and not living in any kind of institution such as a nursing home. The upper age limit for inclusion was set at 85 years, because there was a risk that a large proportion of subjects older than 85 years would not be able to attend the examination.

\section{Ethics}

All subjects received both verbal and written information about the study. Written informed consent was obtained from each participant before enrollment in accordance with the Declaration of Helsinki. Participation in the study was voluntary, and the subjects could end their involvement at any point without giving an explanation. Approval was obtained from the Regional Ethical Review Board in Lund University, Sweden (registration number 566/2008).

\section{Data collection}

Two experienced registered ophthalmic nurses conducted all the functional tests. The same ophthalmic nurse accomplished all tests for a subject in the following order: visual acuity (VA), CS, stereopsis, and perimetry. Standardized protocols for all procedures were used. The question asked about falls was validated. ${ }^{16}$ No information about test results was given until after all the measurements were completed.

\section{Demographics and questions about falls}

Data were collected about sex and age and questions about the occurrence of falls within the last 2 years prior to the study: when the latest fall occurred, how many times a fall occurred, and whether the falls happened indoors or outdoors? We defined a fall according to the World Health Organization's description of a fall as an unexpected change in position (standing, sitting, or lying), which includes gliding, such as from a chair to the floor, and is not caused by an acute illness, eg, stroke. ${ }^{4}$ We considered fallers as those who had fallen within 2 years before the eye examination.

\section{Visual acuity}

Monocular VA was measured with the habitual correction at $2 \mathrm{~m}$ using Early Treatment Diabetic Retinopathy Study (ETDRS) distance charts trans-illuminated with a chart illuminator. ${ }^{17}$ The charts were designed to test VA at a defined test distance. The VA was estimated by scoring all correctly identified letters down to the smallest ones, and the score was then converted into decimals.

Binocular VA was tested with the habitual correction under standard illumination using a Snellen equivalent acuity chart, minimizing learning effects of the ETDRS chart. All testing took place in the same room with standardized low-light conditions $\left(10 \mathrm{~cd} / \mathrm{m}^{2}\right)$. The chart was installed in a standard light box at a $4 \mathrm{~m}$ distance from the subject. A decimal notation was used for expressing the VA. Even though different scales were used when testing monocular and binocular VA, the results corresponded well. One subject had VA better eye 0.79 and binocular VA 0.80 , while another had VA better eye 1.32 and binocular VA 1.30.

The results of VA were divided into different categories based on visual standards by the International Council of Ophthalmology, ${ }^{18}$ which were recommended to be used when coding according to the International Statistical Classification 
of Diseases and Related Health Problems. ${ }^{19}$ Health problems where each group covers four lines on the ETDRS chart. ${ }^{20}$ Subjects in the categories of moderate, severe, and profound vision loss are said to have low vision (Table 1).

\section{Contrast sensitivity}

CS was determined by the Mars Letter Contrast Sensitivity Test (Mars Perceptrix Corporation, Chappaqua, NY, USA), a test further developed from the Pelli-Robson contrast sensitivity test to improve the accuracy for near testing using a simple definite scoring system with reference to existing norms. ${ }^{21,22}$ The viewing distance was a near refraction distance, and the chart was placed on a table at a distance of $40 \mathrm{~cm}$. The luminance was $85 \mathrm{~cd} / \mathrm{m}^{2}$ in the chart's background and checked with a photometer before each test. Visible reflections and glare from the chart's surface were inhibited. The subjects wore appropriate near correction or their habitual distance correction with an addition of $+2.00 \mathrm{D}$. The CS was tested both monocularly and binocularly using different charts for each test to minimize letter sequence learning effects. Only the letters C D H K N O R S V Z were accepted as responses, and the CS was estimated by the lowest contrast letter read by the subject. The test was stopped after two consecutive misses.

The norms for CS are profound CS loss $<0.48 \log$ units, severe CS loss between 0.52 and $1.00 \log$ units, and moderate CS between 1.04 and $1.48 \log$ units. ${ }^{22}$ The normal score for people older than 60 years of age is $1.52-1.76 \log$ units.

\section{Stereoscopic vision}

Stereoscopic vision was tested by Lang-II stereopsis test, which is used for screening examinations. ${ }^{23}$ The test is based on principles of random dots, where four different figures emerge when looking at a card viewed from a distance of $40 \mathrm{~cm}$. The figures represent a monocular visible star, an

Table I Definitions of different levels of VA according to visual standards by the International Council of Ophthalmology ${ }^{18}$ using ETDRS and Snellen equivalent charts

\begin{tabular}{lll}
\hline ICD classification & $\begin{array}{l}\text { Monocular VA; } \\
\text { ETDRS chart }\end{array}$ & $\begin{array}{l}\text { Binocular VA; Snellen } \\
\text { equivalent acuity chart }\end{array}$ \\
\hline Normal vision & $\geq 0.8$ & $\geq 0.8$ \\
Mild vision loss & 0.79 to $\geq 0.32$ & 0.63 to $\geq 0.32$ \\
Moderate vision loss & 0.31 to $\geq 0.125$ & 0.25 to $\geq 0.125$ \\
Severe vision loss & 0.120 to $\geq 0.05$ & 0.10 to $\geq 0.05$ \\
Profound vision loss & 0.04 to $\geq 0.02$ & 0.04 to $\geq 0.02$ \\
Blindness & $\leq 0.019$ & $\leq 0.016$ \\
\hline
\end{tabular}

Note: Data from International Council of Ophthalmology. ${ }^{18}$

Abbreviations: ETDRS, Early Treatment Diabetic Retinopathy Study; ICD, International Classification of Diseases; VA, visual acuity. elephant, a car, and a moon of 600 seconds, 400 seconds, and 200 seconds of arc. Negative stereopsis was defined as not being able to detect any or only the monocular figure, doubtful stereopsis was defined as detecting and locating the figure at 600 seconds of arc, and positive stereopsis was defined as being able to locate and name at least the figure at 400 seconds of arc. When testing, room light was used. The subjects wore appropriate near correction, or their habitual distance correction with an addition of $+2.00 \mathrm{D}$. The card was put at a distance of $40 \mathrm{~cm}$ in a fronto-parallel position. To prevent monocular recognition, only minimal head movement was permitted to facilitate optimal viewing.

\section{Perimetry}

The visual fields (VFs) were tested using the 30-2 SITA Standard program of the Humphrey Field Analyzer 740i (Carl Zeiss Meditec, Dublin, CA, USA). The subjects had their presenting correction adjusted to near vision and with spherical equivalent refraction when the cylinder was equal to or less than $-2 \mathrm{D}$. If the cylinder was more than $-2 \mathrm{D}$, the cylinder was used. A short demo test was run before the examination started. An ophthalmic nurse was available to supervise the subject during the whole test if needed.

The numerical mean deviation (MD) value standing for the global deviation from an age-corrected normal VF was used to describe the global VF status. The manufacturer provided reference limits for normal MD values. We used the two reference limits at the $P<5 \%$ and $P<0.5 \%$ levels as cutoff to classify field having normal and depressed light sensitivity.

All VF printouts were also subjectively assessed for the location of possible VF defects. In addition, the integrated VF (IVF) index ${ }^{24}$ incorporated in the Progressor software (Version 3.3; Medisoft Incorporated, Leeds, UK) was used to estimate the binocular VF. IVF is an index where the sensitivity of each corresponding location in right and left monocular VF is merged. All 76 corresponding locations in the 30-2 test point pattern were scored and summarized. A summary value score of 0 is considered normal, and a score of 152 is considered a completely defective IVF. We used median split for turning IVF scores into two categories: better or worse binocular VF. Printouts of binocular fields were also subjectively assessed for the registration of any binocular field loss.

\section{Spectacles}

We registered if the subjects had any kind of lenses for refractive errors and the type of lenses for correction: single vision, bifocal, progressive, or multifocal. 


\section{Statistical analysis}

To determine an appropriate sample size, power analysis was made by using MedCalc Statistical Software (Version 11.4.2.0; MedCalc Software bvba, Ostend, Belgium) based on the prevalence of visual impairment with a VA better eye of 0.6 or less in a population similar to the study's Swedish conditions ${ }^{25}$ and the estimated number of falls among older people. ${ }^{2}$ To achieve a statistical power of 0.80 at a level of significance of $P<5 \%$, we required 211 participants.

The Statistical Package for Social Sciences (Version 20.0.0.2; IBM Corporation, Armonk, NY, USA) was used to analyze the data. Descriptive statistics were calculated for demographics and various functional tests. The association between functional tests and any fall reported during the last 2 years was analyzed by univariate logistic regression analyses and chi-square tests. A sub-analysis was performed to compare those reporting recurrent falls, which were defined as two or more falls reported during the last 2 years, with the non-fallers.

\section{Results}

A total of 298 subjects in the age group of 70 to 85 years were invited to participate in the study, and 212 (71\%), comprising 94 men and 118 women, did so. The study took place between February 2009 and March 2010. Of the 86 who declined participation, 24 spontaneously stated reasons such as a recent contact with an ophthalmologist or serious health problems. No data of an individual's specific age was obtained when receiving data from the Swedish populationbased listings. The number subjects between 70 and 74 years of age was 96, between 75 and 79 years of age was 61, and between 80 and 85 years of age was $65(n=212)$. The mean age of those who participated was 76 years, with no statistical differences in sex. Of those who participated, $63 \%$ were cohabiting or married and $33 \%$ were single (data were missing for eight subjects). Thirty-two percent lived in a flat and $68 \%$ lived in a villa.

When the subjects were asked about the occurrence of falls, $38 \%(n=80)$ reported that they had fallen at least once during the last 2 years, and 38 subjects reported two or more falls. No significant differences were found between men and women, $33 \%$ of the men and $42 \%$ of the women reported falls, $P=0.20$. Approximately $55 \%$ of those who fell were in the age group ranging from 70 to 74 years, the corresponding proportion of fallers for the age group ranging from 75 to 79 years was $27 \%$, and in the oldest age group it was $18 \%$. The differences between the age groups were not statistically significant, $P=0.18$. Among the participants who reported falling at least once during the previous 2 years, $50 \%$ reported one fall, $20 \%$ two falls, $10 \%$ fell three times, $2 \%$ four falls, and $14 \%$ reported more than four falls. Three of those who had fallen could not remember the number of falls that occurred. Approximately $40 \%$ fell within the last year. Sixty-three percent of the men and $43 \%$ of the women fell outdoors.

\section{Visual acuity}

The majority, 145 (68\%) of the 212 subjects, had normal VA in the better eye. The proportion with normal VA in the better eye was bigger among the fallers than nonfallers, $79 \%$ and $62 \%$, respectively. Mild VA loss eye was the most common classification among those having non-normal VA, and severe or profound loss was seen in three subjects only, both among the non-fallers (Figure 1). Binocular VA with habitual correction was tested in 208 subjects $(n=212)$. Normal binocular VA was seen in $89 \%$ of subjects; with $95 \%$ of the fallers and $90 \%$ of the nonfallers having normal binocular VA. Very few had worse than mild VA loss (Figure 1). The odds ratio (OR) suggested that falls occurred more often in subjects with some degree of VA loss than in subjects with normal VA. There was a significant association between falls and VA better eye, $P=0.013$, but not for binocular VA; however, the $95 \%$ confidence interval was wide (Table 2). No significant association was seen between VA better eye or binocular VA and recurrent falls.

\section{Contrast sensitivity}

CS was tested in all 212 subjects. According to the classification of the International Classification of Diseases scale, 67\% of all subjects had normal CS in the better eye, $68 \%$ of the fallers and $67 \%$ of the non-fallers. Moderate CS loss was the most common classification among those having non-normal CS; the number was $30 \%$ among the fallers and $32 \%$ among the non-fallers. Very few had severe or profound CS loss (Figure 1). Eighty-four percent of all subjects had normal binocular CS, slightly more among fallers than non-fallers at $86 \%$ and $83 \%$, respectively. No association between falls and CS was observed. The OR for CS better eye was 1.04, indicating that CS loss was slightly more common among fallers than among non-fallers. However, the OR for binocular CS was 0.60 , indicating that loss was more common among the non-fallers than the fallers, but the confidence interval were wide, in particular for the better eye CS (Table 2). No significant association was seen between CS better eye or binocular CS and recurrent falls. 


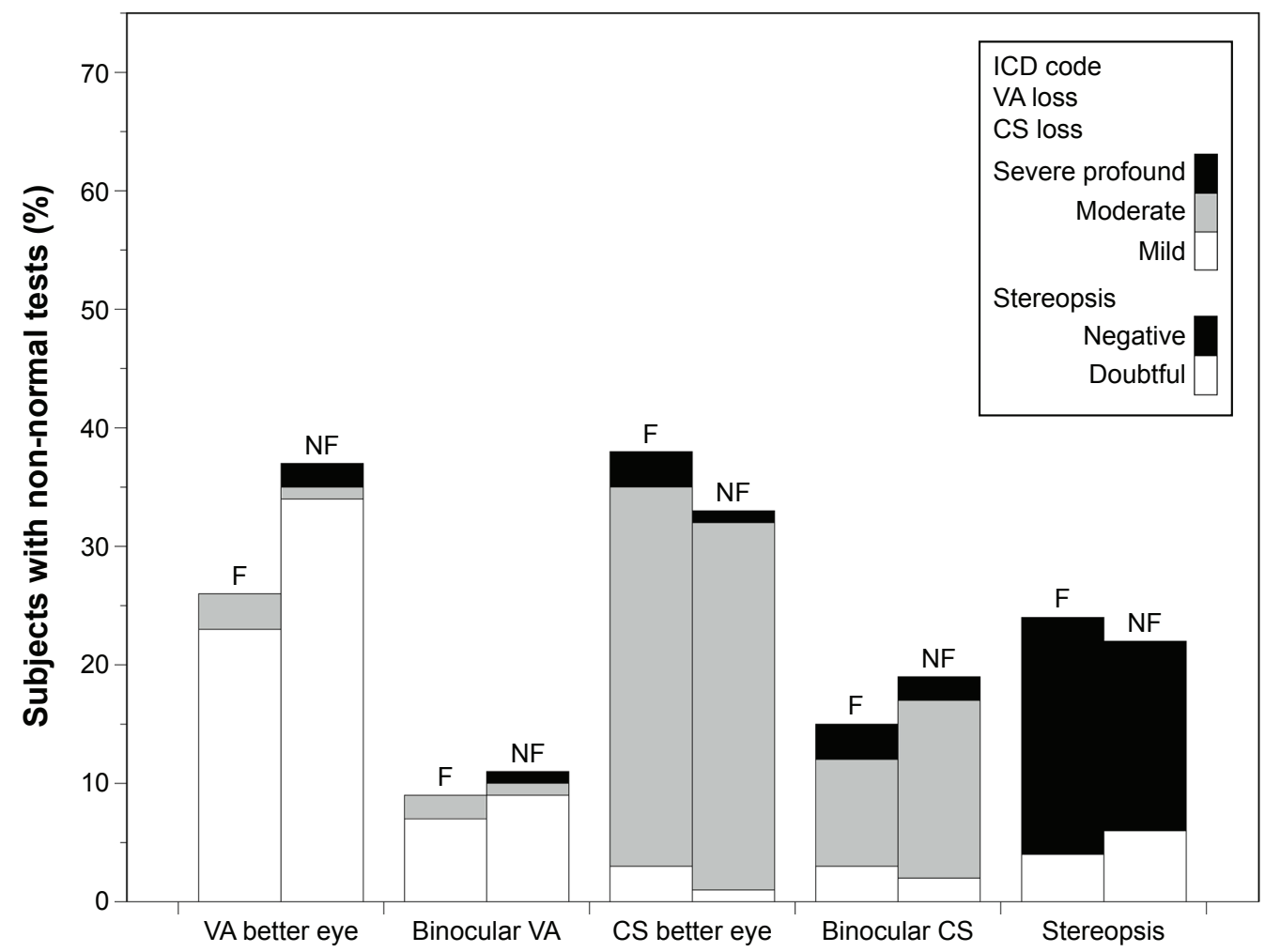

Figure I Proportion of subjects, F, and NF, with non-normal visual test results.

Notes: VA was more often slightly reduced among the NF than F. Severe or profound VA loss was seen in a few subjects among the NF only. Reduced CS in the better eye was slightly more common among F than NF; the opposite was true when testing CS binocularly. Doubtful or negative stereopsis was just slightly more common among the $\mathrm{F}$ than NF.

Abbreviations: CS, contrast sensitivity; F, fallers; ICD, International Classification of Diseases; NF, non-fallers; VA, visual acuity.

\section{Perimetry}

The VF was tested in 210 subjects. The median MD value in the better eye was $-2.02 \mathrm{~dB}$, and ranged from -26.95 to $1.63 \mathrm{~dB}$. Forty-eight percent of all tested subjects were below the $P<5 \%$ MD reference limit and $24 \%$ below the $P<0.5 \%$

Table 2 Visual function tests as presumed risk for falls vs no falls

\begin{tabular}{lllll}
\hline Visual function tests & P-value & OR & \multicolumn{2}{l}{$\mathbf{9 5 \%} \mathbf{C l}$} \\
\cline { 3 - 6 } & & & Lower & Upper \\
\hline VA, better eye & 0.013 & 2.26 & 1.19 & 4.29 \\
VA, binocular & 0.37 & 1.58 & 0.59 & 4.26 \\
CS, better eye & 0.90 & 1.04 & 0.58 & 1.88 \\
CS, binocular & 0.23 & 0.60 & 0.26 & 1.37 \\
Stereoscopic vision & 0.25 & 0.71 & 0.40 & 1.27 \\
Perimetric MD, better eye 5\% & 0.37 & 0.78 & 0.44 & 1.36 \\
Perimetric MD, better eye 0.5\% & 0.21 & 0.66 & 0.35 & 1.26 \\
Monocular VF defects, lower & 0.28 & 0.70 & 0.37 & 1.34 \\
quadrants in one or both eyes & & & & \\
Binocular VF defects, lower quadrants & 0.20 & 1.67 & 0.76 & 3.67 \\
IVF defects, median cutoff & 0.67 & 1.13 & 0.65 & 1.98 \\
\hline
\end{tabular}

Notes: The ORs represent the odds of falls opposed to normal visual function. ${ }^{a}$ Cutoff for $M D$ at the $P<5 \%$ level for outside normal limits. ${ }^{b} C u t o f f$ for $M D$ at the $P<0.5 \%$ level for outside normal limits.

Abbreviations: $\mathrm{Cl}$, confidence interval; $\mathrm{CS}$, contrast sensitivity; IVF, integrated visual field; MD, mean deviation; OR, odds ratio; VA, visual acuity; VF, visual field. limit. There was no association between MD values outside the normal limits and falls (Table 2). The binocular VF, as defined by the IVF scores, was not significantly associated with falls (Table 2). Slightly more fallers than non-fallers had a worse IVF score above the median (four points); the proportions were $52 \%$ and $49 \%$, respectively. Subjective assessment of VFs yielded field loss in the lower hemifield in one or both eyes in $28 \%$ of the fallers and $21 \%$ of the nonfallers. When subjectively assessing the IVFs, 29 (14\%) of the subjects showed defects in the lower hemifield; of those, 14 had fallen. No association with falls and binocular VF defects in the lower hemifield was seen (Table 2). No significant association was seen between any of the perimetric variables and recurrent falls.

\section{Stereoscopic vision}

Fifty-seven percent of all subjects were tested with positive stereopsis, $5 \%$ with doubtful and $18 \%$ with negative stereopsis. Among the fallers, $20 \%$ had negative stereopsis and among the non-fallers $17 \%$ had negative stereopsis (Figure 1). No significant association between falls and 
stereopsis was seen; the OR was 0.71 , indicating fewer falls among the subjects with some degree of defective stereoscopic vision than those with normal stereoscopic vision, but again, the confidence interval was wide (Table 2). Recurrent falls were significantly more frequent in subjects with lack of stereopsis, $\mathrm{OR}=3.1$ and $P=0.002$.

\section{Spectacles}

Examination of habitual corrective lenses showed that $10 \%$ of the fallers had no correction for distance, $11 \%$ wore single-vision spectacles, and 79\% wore bifocal or progressive lenses. The corresponding figures for non-fallers were $25 \%, 8 \%$, and $67 \%$. There was no significant association between single falls and type of refractive lenses $(P=0.078)$ or recurrent falls $(P=0.15)$.

\section{Discussion}

Falls were common, and $\sim 40 \%$ of all subjects had reported at least one fall within 2 years prior to the visual function examinations but visual functional loss was considerably less common than falls. The majority of subjects presented normal results in most of the functional tests: $90 \%$ had normal binocular VA, $85 \%$ had normal binocular $\mathrm{CS}$, and $\sim 80 \%$ had positive stereopsis. With respect to VFs, $106(50 \%)$ subjects had MD values below the normal limits at the $P<5 \%$ level in the better eye, and $\sim 50 \%$ of these had even worse MD values below the $P<0.5 \%$ level. The large percentage of eyes with significantly depressed MD values at the $P<5 \%$ level can possibly be explained by mild cataract, which is common in subjects older than 70 years of age. ${ }^{26}$ However, we did not assess the grade of cataract, but believe it had to be mild in most eyes since VA was unaffected or just mildly reduced in the vast majority of subjects. Regarding MD, a more likely explanation for the reduction in MD values than cataracts may be the lack of perimetric experience of the subjects included in the current study, because it is known that learning effects in subjects naive to perimetry has been thoroughly studied and reported. ${ }^{27,28}$ Nevertheless, the only significant association found between visual function and one or more fall was VA better eye, which was not significantly associated with recurrent falls. Further, binocular VA was not associated with falls, making it difficult to draw any firm conclusions about the role of VA for the risk of falling. ${ }^{29}$ On the other hand, there was a significant association between recurrent falls and lack of stereopsis, $\mathrm{OR}=3.1$ and $P=0.002$.

The subjects were randomly selected from the population of independently living older people between 70 and 85 years of age and $71 \%$ of all invited people participated in the study, which may be considered reasonably high. We chose not to invite subjects younger than 70 years since previous studies have reported that visual function is essentially well preserved in subjects younger than 70 years of age. ${ }^{30,31}$ An upper limit of 85 years of age was set since we feared that a large proportion of subjects older than 85 years would not be able to attend the examination. It is possible that we may have found a higher number of visually impaired among subjects older than 85 years, because increasing age has been reported to be an independent risk factor for both decrease in visual ability and ocular diseases, and falls. ${ }^{1,32,33}$ It is also possible that visually impaired subjects who already had contact with eye health care and/or low vision centers chose not to participate. All data on visual function were collected prospectively, and all measurements were obtained at the Department of Ophthalmology, where the test conditions were optimal and standardized and if needed, an ophthalmologist could be consulted. Because of the importance of equivalence when instructing the subjects and performing the measurements, two experienced ophthalmic nurses were using not only standardized visual measurements but also written instructions. Therefore, our study is reliable, repeatable, and reproducible.

We believe that testing of binocular vision is of importance when evaluating possible risks of falling and subsequently measured both when testing VA and CS. When it came to VFs, we used the IVF, ${ }^{24}$ both by counting scores and by subjectively assessing printouts for the detection of binocular VF defects. We also tested VA and CS, both monocularly and binocularly. A minor blunder occurred when testing monocular VA using distance correction on ETDRS charts designed for testing at $2 \mathrm{~m}$ distance. The majority of subjects were later retested adding $+0.5 \mathrm{D}$ to the distance correction with no or minimal change in VA.

It has been suggested that the degree of visual function loss is underestimated when measuring standard VA during optimal conditions such as pertained to all measurements performed in our study. ${ }^{30}$ It can be explained by home conditions, eg, insufficient lighting being a problem likely to interact with possible mild visual problems. A recently published study compared conditions in a clinic, where various measurements were performed to the conditions in the subjects' homes. ${ }^{34}$ More than half of the population performed better when tested in a clinical setting than in their homes. This finding may partly explain why associations with falls only occurred in testing VA better eye and lack of stereoscopic vision in this study. On the other hand, when testing conducted under optimal standardized conditions, 
the outcome is comparable among various subjects, and also across different studies.

Data about falls were collected retrospectively. This method is of course not as reliable as a prospective longitudinal approach following subjects over time, which can record new falls. Subjects tend to forget whether or not they have fallen: a longitudinal prospective study on falls revealed that up to $30 \%$ of subjects did not recall falling at the end of the 12-month follow-up period..$^{35}$ Interviewing subjects about previous falls is therefore not optimal, but it is the only possible approach since we were not using a longitudinal prospective design. Therefore, there may be subjects who have fallen and not reported it. There may also be subjects who have taken action in correcting refractive errors or who had cataract surgery after the reported fall occurred. One would expect that such interventions would decrease the risk of poor vision-induced falls and could explain at least some of our results, but an interesting study by Cumming et $\mathrm{al}^{36}$ found that the risk of falling actually increased after eye examinations followed by vision-related interventions to prevent falls among older people living independently.

Since no data of each individuals' specific age were obtained when receiving data from the Swedish population-based listings, it is not possible to evaluate whether age may be one of the reasons why some chose not to participate in our study. In one big population-based study, where visual function was investigated, the participation declined with age, with no differences in sex. ${ }^{37}$ However, this may be of importance to the results of our study, since it is known that visual function naturally declines with age and the prevalence of age-related ocular diseases increases. ${ }^{32}$

In the major population-based study, the Blue Mountains Eye Study, associations between falls and VA were reported, ${ }^{38}$ while in another study, no associations were found using visual functional tests similar to the tests performed in our study. ${ }^{39}$ The results of research investigating whether vision and falls among older people have any kind of association are inconsistent. ${ }^{15}$ However, the result of our study is similar to previous research where people were more likely to fall if a unilateral visual impairment was detected. ${ }^{40-42}$ One of these studies included subjects from 49 years of age and older, ${ }^{40}$ while another study included only subjects with low vision. ${ }^{41}$ Regarding stereoscopic vision, researches have shown a significant association not only with recurrent falls but also with fractures. ${ }^{15,29}$ In our study, only a few needed hospital care though.

There is an inability to adjust for confounding variables even in large population-based studies such as the Blue
Mountain Eye study. ${ }^{42}$ In studies where the impact of visual impairment in populations with specific eye diseases, eg, glaucoma, age-related macular degeneration, or cataract, was investigated, falls were clearly associated with visual loss..$^{8-10,43}$ In our study, very few subjects had severe or profound visual loss, which may explain the difference in our results compared to these studies, since only VA better eye was associated with falls. However, Chou et $\mathrm{al}^{44}$ reported that screening for impaired vision in older adults with the goal of improving vision, function, and quality of life may not be effective and could be associated with an increased risk of falls.

A number of studies have investigated the risk of falls in different kinds of populations of community-dwelling older people. ${ }^{11,37,45-53}$ Most of these studies showed that falls were more common in subjects with reduced function in various visual parameters than in subjects with normal functions, while some of the studies ${ }^{47,49-54}$ also included nonvisual factors, eg, urinary incontinence, impaired mobility, use of analgesics, change in housing conditions, etc, which often showed stronger associations (higher OR) with falls than did the visual parameters. It is also of importance to take into account that some of the studies were performed several years ago, investigating populations in the age group between 43 years and 99 years and in different kinds of living. The visual tests in the studies are performed in different kinds of conditions and different kinds of measurements are performed, which makes it difficult to make any distinct comparisons not only between our study and these studies but also between other studies. Yet, considering these and our results we believe there are other, more powerful predictors of falls, and that visual ability may merely be one contributor.

As the demographics are predicted to change, regardless of country, even more knowledge is needed to be able to meet the increasing aging society. ${ }^{2}$ All falls do not require health care, and therefore health care providers only meet a few of those who have fallen. Since injury prevention among older people is a major topic today, a holistic approach is feasible in promoting healthy aging and especially among non-institutionalized independently living older people who we seldom meet in health care. Therefore, other proactive actions than today's are needed regarding visual ability as both a predictor and contributor of falling, because of its impact on well-being and healthy aging.

\section{Conclusion}

In our study, associations between unilateral VA and falls and lack of stereoscopic vision and recurrent falls were found in 
an independently living old population with no differences in sex. The role of VA, however, was not sustained when analyzing risks for recurrent falls. The majority of the subjects presented normal results in most of the visual function tests, but falls were common. We believe that there may be more powerful predictors of falling among independently living older people, though visual ability may be a contributor. Falls are common, and a major problem in older people appears to be a complex issue; the individual's whole life situation has to be considered when identifying elderly individuals at risk of falling.

\section{Author contributions}

All authors contributed toward data analysis, drafting and critically revising the paper and agree to be accountable for all aspects of the work.

\section{Disclosure}

The authors report no conflicts of interest in this work.

\section{References}

1. National Institute for Clinical Excellence. National Practice Guideline for the Assessment and Prevention of Falls in Older People. London: NICE; 2004

2. Organisation for Economic Co-operation and Development. $O E C D$ Studies in Risk Management - Sweden. Safety of the Elderly. Paris: OECD; 2006.

3. Gyllensvärd H. Accidental Falls in Elderly People: A Socioeconomic Analysis and Effective Preventive Measures. Östersund: Swedish National Health Institute of Public Health; 2009. Report No 2009:01.

4. World Health Organization [webpage on the Internet]. WHO Global Report on Falls Prevention in Older Age. 2007. Available from: http://www.who.int/violence_injury_prevention/other_injury/falls/en/ index.html. Accessed November 8, 2015.

5. Bergman B, Sjöstrand J. A longitudinal study of visual acuity and visual rehabilitation needs in an urban Swedish population followed from the ages of 70 to 97 years of age. Acta Ophthalmol Scand. 2002; 80(6):598-607.

6. Lord SR, Dayhew J. Visual risk factors for falls in older people. $J$ Am Geriatr Soc. 2001;49(5):508-515.

7. Patino CM, McKean-Cowdin R, Azen SP, et al. Central and peripheral visual impairment and the risk of falls and falls with injury. Ophthalmology. 2010;117(2):199-206.

8. Anastasopoulos E, Yu F, Coleman AL. Age-related macular degeneration is associated with an increased risk of hip fractures in the medicare database. Am J Ophthalmol. 2006;142(6):1081-1083.

9. Black AA, Wood JM, Lovie-Kitchin JE. Inferior field loss increases rate of falls in older adults with glaucoma. Optom Vis Sci. 2011;88(11): $1275-1282$.

10. Harwood RH, Foss AJ, Osborn F, Gregson RM, Zaman A, Masud T. Falls and health status in elderly women following first eye cataract surgery: a randomized controlled trial. Br J Ophthalmol. 2005;89(1): $53-59$.

11. Lord SR, Smith ST, Menant JC. Vision and falls in older people: risk factors and intervention strategies. Clin Geriatr Med. 2010;26(4): 569-581.

12. Black AA, Wood JM, Lovie-Kitchin JE, Newman BM. Visual impairment and postural sway among older adults with glaucoma. Optom Vis Sci. 2008;85(6):489-497.
13. Wood JM, Lacherez P, Black AA, Cole MH, Boon MY, Kerr GK. Risk of falls, and other injuries resulting from visual impairment among older adults with age-related macular degeneration. Invest Ophthalmol Vis Sci. 2011;52(8):5088-5092.

14. Haymes SA, Leblanc RP, Nicolela MT, Chiasson LA, Chauhan BC. Risk of falls and motor vehicle collisions in glaucoma. Invest Ophthalmol Vis Sci. 2007;48(3):1149-1155.

15. Salonen L, Kivelä SL. Eye diseases and impaired vision as possible risk factors for recurrent falls in the aged: a systematic review. Curr Gerontol Geriatr Res. 2012;2012:271481.

16. Källstrand Eriksson J, Baigi A, Buer N, Hildingh C. Perceived visionrelated quality of life and risk of falling among community living elderly people. Scand J Caring Sci. 2013;27(2):433-439.

17. Ferris FL, Sperduto RD. Standardized illumination for visual acuity testing in clinical research. Am J Ophthalmol. 1982;94(1):97-98.

18. International Council of Ophthalmology [webpage on the Internet]. Visual Standards. Aspects and Ranges of Vision Loss with Emphasis on Population Surveys. 2002. Available from: http://www.icoph.org/ downloads/visualstandardsreport.pdf. Accessed March 2, 2016.

19. World Health Organization [webpage on the Internet]. International Classification of Diseases. Available from: http://www.who.int/ classifications/icd/en/. Accessed March 2, 2016.

20. Early Treatment Retinopathy Study Research Group. Early treatment diabetic retinopathy study design and baseline characteristics. ETDRS report number 7. Ophthalmology. 1991;98(5 suppl):741-756.

21. Arditi A. Improving the design of the letter contrast sensitivity test. Invest Ophthalmol Vis Sci. 2005;46(6):2225-2229.

22. Thayaparan K, Crossland MD, Rubin GS. Clinical assessment of two novel contrast sensitivity charts. Br J Ophthalmol. 2007;91(6):749-752.

23. Nüssgens Z, Czerwonka B, Roggenkämper P. Examinations on the new LANG test. Strabismus. 1993;1(2):69-73.

24. Crabb DP, Viswanathan AC. Integrated visual fields: a new approach to measuring the binocular field of view and visual disability. Graefes Arch Clin Exp Ophthalmol. 2005;243(3):210-216.

25. Hirvelä $\mathrm{H}$, Laatikainen L. Visual acuity in a population aged 70 years or older: prevalence and causes of visual impairment. Acta Ophthalmol Scand. 1995;73(2):99-104.

26. Klein BEK, Klein R, Lee KE. Incidence of age-related cataract: the Beaver Dam Eye Study. Arch Ophthalmol. 1998;116(2):219-225.

27. Heijl A, Lindgren G, Olsson J. The effect of perimetric experience in normal subjects. Arch Ophthalmol. 1989;107(1):81-86.

28. Wild JM, Pacey IE, O'Neill EC, Cunliffe IA. The SITA perimetric threshold algorithms in glaucoma. Invest Ophthalmol Vis Sci. 1999; 40(9): 1998-2009.

29. Lord S. Visual risk factors for falls in older people. Age Ageing. 2006; 35(suppl 2):ii42-ii45.

30. Haegerstrom-Portnoy G, Schneck ME, Brabyn JA. Seeing into old age: vision function beyond acuity. Optom Vis Sci. 1999;76(3):141-158.

31. Rubin GS, West SK, Munoz B, et al. A comprehensive assessment of visual impairment in a population of older Americans: the SEE Study, Salisbury Eye Evaluation Project. Invest Ophthalmol Vis Sci. 1997;38(3): $557-568$.

32. Gunnlaugsdottir E, Arnarsson A, Jonasson F. Prevalence and causes of visual impairment and blindness in Icelanders aged 50 years and older: the Reykjavik Eye Study. Acta Ophthalmol. 2008;86(7):778-785.

33. Owsley C. Aging and vision. Vision Res. 2011;51(13):1610-1622.

34. Bhorade AM, Perlmutter MS, Wilson B, et al. Differences in vision between clinic and home and the effect of lighting in older adults with and without glaucoma. JAMA Ophthalmol. 2013;131(12):1554-1562.

35. Cummings SR, Nevitt MC, Kidd S. Forgetting falls: the limited accuracy of recall of falls in the elderly. J Am Geriatr Soc. 1988;36(7):613-616.

36. Cumming RG, Ivers $\mathrm{R}$, Clemson $\mathrm{L}$, et al. Improving vision to prevent falls in frail old people: a randomized trial. J Am Geriatr Soc. 2007; 55(2):175-181.

37. Ramrattan RS, Wolfs RC, Panda-Jonas JB, et al. Prevalence and causes of visual field loss in the elderly and associations with impairment in daily functioning: the Rotterdam Study. Arch Ophthalmol. 2001;119(12): 1788-1794. 
38. Ivers RQ, Cumming RG, Mitchell P, Attebo K. Visual impairment and falls in older adults: the Blue Mountains Eye Study. J Am Geriatr Soc. 1998;46(1):58-64.

39. Lamoureux E, Gadgil S, Pesudovs K, et al. The relationship between visual function, duration and main causes of vision loss and falls in older people with low vision. Graefes Arch Clin Exp Ophthalmol. 2010; 248(4):527-533.

40. Hong T, Mitchell P, Burlutsky G, Samarawickrama C, Wang JJ. Visual impairment and the incidence of falls and fractures among older people: longitudinal findings from the Blue Mountains Eye Study. Invest Ophthalmol Vis Sci. 2014;55(11):7589-7593.

41. Lin C-H, Liao K-C, Pu S-J, Chen Y-C, Liu M-S. Associated factors of falls among the community-dwelling older people assessed by annual geriatric health examinations. PLoS One. 2011;6(4):e18976.

42. Yip LY, Khawaja AP, Broadway D, et al. Visual acuity, self-reported vision and falls in the EPIC-Norfolk Eye study. Br J Ophthalmol. 2014; 98(3):377-382.

43. Lamoreux EL, Chong E, Wang JJ, et al. Visual impairment, causes of vision loss, and falls: the Singapore Malay Eye Study. Invest Ophthalmol Vis Sci. 2008;49(2):528-533.

44. Chou R, Dana T, Bougatos C. Screening older adults for impaired visual acuity: a review of the evidence for the U.S. Preventive Services Task Force. Ann Intern Med. 2009;151(1):44-58.

45. Coleman AL, Cummings SR, Yu F, et al. Binocular visual-field loss increases the risk of future falls in older white women. $J$ Am Geriatr Soc. 2007;55(3):357-364.
46. Knudtson MD, Klein BE, Klein R. Biomarkers of aging and falling: the Beaver Dam Eye Study. Arch Gerontol Geriatr. 2009;49(1):22-26.

47. Kuang T-M, Tsai S-Y, Hsu W-M, Cheng C-Y, Liu J-H, Chou P. Visual impairment and falls in the elderly: the Shihpai Eye Study. J Chin Med Assoc. 2008;71(9):467-472.

48. Lord SR, Ward JA, Williams P, Anstey KJ. Physiological factors associated with falls in older community-dwelling women. J Am Geriatr Soc. 1994;42(10):1110-1117.

49. Luukinen H, Koski K, Kivela SL, Laippala P. Social status, life changes, housing conditions, health, functional abilities and life-style as risk factors for recurrent falls among the home-dwelling elderly. Public Health. 1996;110(2):115-118.

50. Nevitt MC, Cummings SR, Kidd S, Black D. Risk factors for recurrent nonsyncopal falls: a prospective study. JAMA. 1989;261(18) 2663-2668

51. Tromp AM, Smit JH, Deeg DJ, Bouter LM, Lips P. Predictors for falls and fractures in the Longitudinal Aging Study Amsterdam. J Bone Miner Res. 1998;13(12):1932-1939.

52. Tromp AM, Pluijm SM, Smit JH, Deeg DJ, Bouter LM, Lips P. Fall-risk screening test: a prospective study on predictors for falls in communitydwelling elderly. J Clin Epidemiol. 2001;54(8):837-844.

53. Freeman EE, Muñoz B, Rubin G, West SK. Visual field loss increases the risk of falls in older adults: the Salisbury eye evaluation. Invest Ophthalmol Vis Sci. 2007;48(10):4445-4450.

54. Langdon R, Johnson M, Carroll V, Antonio G. Assessment of the elderly; it's worth covering the risks. J Nurs Manag. 2013;21(1):94-105.
Clinical Ophthalmology

\section{Publish your work in this journal}

Clinical Ophthalmology is an international, peer-reviewed journa covering all subspecialties within ophthalmology. Key topics include: Optometry; Visual science; Pharmacology and drug therapy in eye diseases; Basic Sciences; Primary and Secondary eye care; Patien Safety and Quality of Care Improvements. This journal is indexed on

Submit your manuscript here: http://www.dovepress.com/clinical-ophthalmology-journal

\section{Dovepress}

PubMed Central and CAS, and is the official journal of The Society of Clinical Ophthalmology (SCO). The manuscript management system is completely online and includes a very quick and fair peer-review system, which is all easy to use. Visit http://www.dovepress.com/ testimonials.php to read real quotes from published authors. 